\title{
Evaluation of a Health Informatics Postgraduate Program
}

\author{
Martha CHARALAMPIDOU ${ }^{1}$, Emmanouil ZOULIAS ${ }^{1}$ and John MANTAS \\ ${ }^{a}$ Health Informatics Laboratory, Faculty of Nursing, National and Kapodistrian \\ University of Athens, Athens, Greece
}

\begin{abstract}
The $4^{\text {th }}$ industrial revolution of informatics and data is an important factor of modern health care provision. The WHO, the EU and other governmental authorities have recognised the new needs. The health care professionals face this change in daily work. The higher education community has responded on time with a wide range of relevant programs. In order to achieve the best results for health care related educational programs an evaluation procedure is needed. In this work a brief part of the evaluation of a Health Informatics program is presented.
\end{abstract}

Keywords. Health Informatics, Postgraduate, Education, Evaluation

\section{Introduction}

Informatics have a key role in health care daily work and further extensions are possible. The technology used in health is supported by a wide range of healthcare products including information technology and healthcare services, like EHR and many more. The World Health Organization has recognized the importance of digital technologies in 2018 [1]. In addition to that European Commission set e-health as a priority [2]. International organizations have set up recommendations to foster educational standards [3]. In the higher education area, there are various undergraduate and postgraduate programs in the field of Health Informatics, Medical Informatics, Bioinformatics, Biomedical Informatics [4], [5]. The evaluation made by students of a health-related educational program results in a safer and improved patient care environment in the $21 \mathrm{st}$ century [6]. This work presents a part of the evaluation results of a Health Informatics Program.

\section{Methods}

The current training curriculum of the postgraduate program on Health Informatics organized by the Faculty of Nursing consists of 3 semesters. The first two semesters include 11 compulsory subjects and 2 compulsory electives. The $3^{\text {rd }}$ semester is for the elaboration of a thesis. The evaluation procedure of the program is a twofold approach with 29 qualitative and quantitative questions regarding the general impression of the students concerning the curriculum, subjects, and teachers. Each student fills in one

${ }^{1}$ Corresponding Author, Martha Charalampidou, Faculty of Nursing, School of Health Sciences, National and Kapodistrian University of Athens, Athens, Greece; E-mail: mcharal@nurs.uoa.gr. 
questionnaire for every subject, during the last lecture. The quantitative responses were analysed using SPSS 24 . The questionnaires are filled in by 20 students yearly.

\section{Results}

The main findings of qualitative questions are that students ask for more practice on database systems and computer networks subjects, this revealed by students' statements like the phrase "although databases subject was very useful and interesting, there should be practical applications". In addition to that more than $20 \%$ state that they need practice on real working hospital information system.

Regarding the quantitative results, each subject receives in the evaluation form a grade among "moderate", "good", "very good" and "excellent" by the students. In this research the average grade of the compulsory courses received, one year before the 2018 curriculum change and one year after, by the students was calculated (Table 1).

Table 1. Overall subjects' evaluation during period of 2017-2020

\begin{tabular}{ccccc}
\hline Years & Moderate & Good & Very Good & Excellent \\
\hline $2017-2018$ & 8,5 & 16,9 & 33,3 & 41,3 \\
$2018-2019$ & 14,3 & 22,2 & 33,5 & 30,0 \\
$2019-2020$ & 6,8 & 13,9 & 37,2 & 42,1 \\
\hline
\end{tabular}

\section{Discussion and Conclusions}

The quantitative results reveal that initially the curriculum change led to an increase in the average "Moderate" opinion from $8,5 \%$ to $14,3 \%$ and led to a decrease in "Excellent" opinion from $41,3 \%$ to $30 \%$. This decrease might be due to the adaption of the teachers and administration to the new curriculum. On the contrary during the second year the average "Moderate" opinion decreased to 6,8\%, and the "Excellent" increases to 42,1\%, which is higher to the old level before the curriculum change. In conclusion the overall acceptance one year after the curriculum change slightly overcame the acceptance one year before. This result is one indicative clue that the change in the curriculum was in a correct route of change.

\section{References}

[1] $71^{\text {st }}$ (Seventy First) World Health Assembly, 2018; Geneva, Switzerland, Availabl;e at https://apps.who.int/gb/ebwha/pdf_files/WHA71/A71_R7-en.pdf?ua=1, Accessed Jan 25, 2021.

[2] Directorate-General for Health and Food Safety. Policies, information and services: eHealth: digital health and care [internet]. Brussels; DG SANTE; 2017, Available at https://ec.europa.eu/health/ehealth/overview_en, Accessed Nov 6, 2017.

[3] Mantas J, Mantas J, Ammenwerth E, Demiris G, et al. Recommendations of the International Medical Informatics Association (IMIA) on Education in Biomedical and Health Informatics. First Rev. Meth Inf Med. 2010 Jan 7;49(2):105-120.

[4] Kolokathi A, Mantas J. Education in Biomedical and Health Informatics: A Mapping Approach. Stud Health Technol Inform. 2018;251:313-316.

[5] Kolokathi A, Hasman A, Chronaki C, at al. Education in Biomedical and Health Informatics: A European Perspective. Stud Health Technol Inform. 2019 Aug 21;264:1951-1952.

[6] Alimisis D., Fengou M., Zoulias E., (2013) "Robotics in Surgery: Designing a Simulator-Based Training Curriculum.” In P. Kommers \& P. Isaías (eds.) Proceedings of the International Conference e-Society 2013, Lisbon, pp. 233-240. 